\title{
Organizational Dynamics and Public Service Ethics in Nigeria
}

\author{
Joseph Nkang Ogar ${ }^{1}$, Nweake Christopher Ude ${ }^{2}$ \\ ${ }^{1}$ Department of Philosophy, University of Calabar, Cross River State. \\ E-mail: nkangjosph@yahoo.com \\ ${ }^{2}$ Federal college of Agriculture, Ishiagu, Ebonyi State. \\ E-mail: theologyude@gmail.com
}

(Received: March-2020; Reviewed: March-2020; Accepted: March-2020;

Avalaibel Online: March-2020; Published: March-2020)

(7) (8) This is an open access article distributed under the Creative Commons Attribution License CC-BY-NC-4.0 @2020 by author (https://creativecommons.org/licenses/by-nc/4.0/)

\begin{abstract}
The selection of 'right man' for 'right job' and his/her orientation in administrative philosophy and social values need to be reinforced by effective systems for ethical administration as they create 'conducive' or 'non conducive' environment Numerous studies have indicated that organization climate and atmosphere will play a dominant role in influencing individuals with appropriate attitudes and skills. Keeping this in view, this work focuses on the important aspects of organization and their impact on ethical behavior of administrators. Some of the important issues raised are to what extent hierarchy influences ethical behavior. How rules and procedures influence administration. Whether ethics institutions and codes of conduct help achieve public service ethics? This method used in this research is context textual analysis.
\end{abstract}

Keywords: Public administration; Organizational Dynamics; Public Service Ethics; Ethics.

\section{INTRODUCTION}

Organizations are made up of various sub units which are related to each other. Major variables of organizational structure are complexity, formalization, centralization and administrative intensity. However, it is difficult to say that these per se have a direct impact on administrative ethics. "It is difficult to establish that the structure of organizations has an independent impact on ethical behavior and outcome. More likely, organizational structure along with organizational climate, individual ethical commitments and numerous other influences work simultaneously and shapes behaviour" (Gabriel 1999). It is the value structure and general practices of organizations, representing organizational culture, which either promote or hinder ethical behavior. Cooper while observing the significance of organizational culture writes that it "... exercise(s) powerful influence over tile employees apart from, and sometimes in opposition to, the formal rules, regulations, procedures and role authority of the managers" (Hunter 2012). 
Recognizing this, we attempt to discuss the relationship between organizational aspects and ethical behavior. Important organizational aspects include hierarchical system, leadership, reward (punishment). The hierarchical system has certain culture associated with it i.e. authoritarianism, career focus, targetosis and adaptative nature and rule orientation of the administrators; Leadership and its role in ethicizing the administration i.e. setting moral codes and ethical 'tone' for the organization and role modeling for ethicizing the administration. Finally ethics institutions and their efficacy in upholding high ethics in administration.

\section{Hierarchy and Ethics}

According to Solomon, the hierarchical structures, while maximizing control, reliability and discipline, fail to promote public service purpose for which they come into existence (2004: 54). They are viewed as insensitive to the dynamics of human behavior. They are said to "erode internal and even external sides of morality, not only in matters of individual success and failure but also in issues that managers face in their daily work" (Pilatti 2006, Duke 2018). Firstly, target orientation of hierarchical structures (means to reach organizational norms of efficiency and effectiveness) raises considerable ethical problems. It while downplaying 'substantive' rationality, upholds 'formal' rationality.

According to Pullen and Rhodes "reaching targets within stipulated time" acquires great importance as it forms the basis of performance appraisal for career development (2015: 54). According to him, "administrators performance is measured on the basis of how much work has been carried out under his/her supervision in the department irrespective of what and how they have done it" (2015: 54). Also that "most of the times work is shown only on paper which gives out the account of how many have worked rather than giving feedback on how it is done, who has benefited and whether it has reached the people for whom it is meant? Who knows what is actually done?" It has many drawbacks. The most important being political pressure to reach targets. In Nigeria, politicians and political parties, of late, are more interested in announcing achievements of their Organizations statistically to win over the vote banks. It limits the scope of administration and administrators for initiative and innovation and that it changes attitude towards the job. It also encourages the members of the services to view their job as task given, the fulfillment of which becomes the main concern. "Infact they (members of service) are committed to the task, not the job" (Pilatti 2006).

Secondly, rules and procedures, drawn to secure loyalty of members, are the most important components of "organizational structure which is relevant to ethical administration (Eze 2015). They lay down boundaries for administrative actions and are accepted and adopted by the administrators. They are required to run the administration smoothly with continuity, consistency, impartiality and fairness and therefore, to ensure ethicality of actions. They are seen as the guidelines to take decisions without personal bias and dilemmas. However, they have been raised to the status of institutions by the systems and further reinforced by the administrators who rigidly adhere to them without deliberating over their correctness and applicability with change in time and demands on administration. Moreover, their continuation over a long period without deliberations and subsequent amendments, they may not only become irrelevant but also may not serve their purpose.

Thirdly, various forces at interplay (mainly the pivotal position occupied by members of superior civil services, availability of information and self-perception that 'they are of intellectually of high caliber') in the organizational context made them 'less consultative' in their 
functioning (Agbin \& Chukwujioke 2018; Duke 2019). However, Okotoni (2015) hold that they are 'interested in consulting with the concerned parties but required interaction and participation is not forthcoming from them'. But on further enquiry as to how (what channels) they would like to go about consultations, many did not have constructive ideas. While some suggested bodies like community meeting, citizen fora as the best means others expressed that they are not effective and that they have lost their significance.

The structural aspects of organization orient the members to develop certain attitudes as discussed above. These, make them career oriented, centralize powers, arrogant ${ }^{\wedge}$ rule-oriented, inaccessible, non-innovators, sidelining the more important aspect of 'service to the public' which is the highest ethics in any democratic system. ' An in-depth analysis of these findings in terms of behavior predisposition and action profile would suggest that a group characterized with the above orientation is likely to be "concealed", indulge in ruthless career advancement and demonstrate low value for contribution to organizational growth and social development (Akinmayowa 2008).

The shortcomings presented by organizational structures (which are imminent and cannot be avoided) can be effectively dealt with by the leadership. Leadership, shapes organizational climate by laying down norms and values. It can also orient and/or re-orient value structures of the Organizations by adopting appropriate policies and practicing them. It is "hailed as the crucial variable in the changing or re-orienting of organizational cultures" (Ali Ibbi 2016). It forms the matter of discussion in the next section.

\section{Leadership and Public Service Ethics}

Leadership plays a very critical role in maintaining organizational ethics. In fact; its role is considered as that of re-orienting organizational culture and ethics. Nwabuzor (2005) writes that "the unique and essential function of leadership is the manipulation of culture". The leaders shape the ethical norms of the organization by deliberate role modeling, by allocating rewards and status and by fixing criteria for recruitment selection, promotion, retirement and excommunication (Akpakip 2017). However, it is their adherence to set ethical norms which is more important in building organizational culture. ".. if you verbally encourage ethical conduct but make exceptions for yourself, you" subordinates will pay attention to the moral exceptions rather than your nice words and the organization will be shaped accordingly" (Okotoni 2015).

Reflecting on modem day administration (particularly post -1970's) Agbin \& Chukwujioke feel that role-modeling has no more remained in the service (both within and without the hierarchy). Though both first and second generation respondents hold this view, more number of second generation administrators appear to have experienced this. They strongly feel that if the superiors are strict in the observation of rules and codes "others in the organization automatically follow the suit". Okotoni (2015) is of the opinion that between five and ten years after recruitment it is possible to inculcate ethical values among the juniors provided the seniors in the service guide them in right direction. ... if the seniors are responsive, ethical and qualified, the younger generation will inculcate these values by trying to adopt them in their behavior and therefore, they can be molded to be ethical, sensitive and responsive" (43).

Many authors (Okotoni 2015; Akinmayowa 2016; Nwabuzor 2005) felt that their seniors were worth emulating and that they did guide their behavior effectively. Akpakip's study brings out this aspect most effectively. The author quotes a respondent (of 1958 batch) saying 'if I am a good officer today, then the credit is mainly due to my collector'. The training in norms and 
values of the service, by the leaders within the service, begins at the Academy itself and continues for a few years into the service (particularly during early postings). Though many examples of inculcating values through exemplary leadership may be found in the administrative history of Nigeria. Daramola (2013) study started otherwise.

The leadership within the hierarchy becomes so significant that it shapes the behavior of administrators for their entire tenure. Omilusi (2018) felt that seniors encouraged juniors to follow established norms of services. Abu, who served as Chief Secretary of Edo State in mid1970s, said "when I was a junior he (referring to his superior Chief Secretary) encouraged me and others to treat him like an affectionate older brother, argue with him on governmental matters with frankness". This culture was further carried out by others. Continuing Mukerji said that in doing so he laid down norms of office behavior and we, in turn, have become senior and try to follow his example' (Salam \& Musa 2017).

However, the same cannot be said of Adesopo (2013). He feel that the seniors do not give required amount of attention and interest to their administrative difficulties. Thinking alike, another first generation respondent said that "the senior officers appear not to reflect on their responsibilities and its impact on the ethical behavior of the junior members of the service" (Blom 2019). This reflects to have affected the service orientation of the personnel. An administrator feels that "if ethical officers are encouraged public administration will become service oriented. But exactly opposite is occurring making it more non-service oriented. Many seniors do not encourage good work and honesty. Therefore, honest officers are discouraged".

From the above reflections it may be inferred that the leadership, which was of very high standards, is gradually deteriorating in its quality leaving the younger members of the service 'directionless' and 'shaping' them inappropriately. However, this deficiency could, to a very minute extent (as there is no effective alternative to leadership), be filled by peer groups which serve an informal but significant role in 'shaping' human behavior in the organization. It formulates the contents of our next section.

\section{Reward (Punishment) Pattern}

Reward (punishment) patterns are evolved by organizations to control employee behavior (Rhees 2013). They encourage loyalty to organizational goals and overlook individual ethical actions. However, the leadership may encourage ethical conduct by identifying and rewarding such conduct But "one difficulty with direct rewards to individuals is impossibility of measuring systematically how ethically people are conducting themselves under routine conditions" (Kweon. 2017: 76). The scholar further says that" the most effective approach may be to reserve rewards for those less frequent more dramatic, identifiable instances of ethical courage within the organization..." (Kweon. 2017: 77). Some common rewards identified are recognition, promotions, increase in the salary etc,. However, rewards identified most frequently by our respondents are recognition of good work, transfers to favourable departments and places, timely promotional policies, and non-interference' of political functionaries in administrative matters. Ewing feel that there are no rewards for good work and even if there were some they are not utilized properly and are distorted. An administrator said that "as a policy reward system presupposes that whoever is good at work is rewarded". But in reality politicians decide who should be rewarded and punished? And what should be the basis of such rewards and punishments? 
Recognition of good' work by the organization is the most appealing of all the rewards according to our respondents. Ewing feel that it would encourage them in their work. However, according to him it is not forthcoming. On the contrary attempts are constantly made to discourage them either by ignoring or by castigating such efforts. Their general opinion may be summarized as:

(a) Basically good work is not recognized. Many people accept public services, as a matter of honor, even at the cost of many sacrifices. What they expect is a pat on the back. But they rarely get it.

(b) If you are honesty there is no recognition. Officers who work in alliance with politicians will get honors, medals, good postings and recognition. "Frustration sets in damaging administrative ethics". Recollecting from her experience an administrator said that "an officer known for hard work, honesty and uprightness was summoned before the Public Accounts Committee, at the behest of others in the organization, and questioned. If this is the case how can administration move smoothly and public service ethics be ensured?

Placement to coveted and important positions and transfer to convenient places as rewards for ethical actions are also missing according Dumbili \& Sofadekan (2016). According to them transfers, postings and provisions of other facilities do not depend on good' work. They are decided by the political masters. This, infact has turned to the disadvantage of enthusiastic and honest administrators of whom the government does not lac". Conversely the political leadership (which has come to control service conditions of administrators) 'rewards unethical behavior' if it is to be benefited by protecting personnel involved. The general view of most author on this is that "ninety per cent of the times, guilty who should be punished, in the strict sense to avoid recurrence of immoral and unethical activities go scot free and unpunished". A police officer recollecting from his experience said that he "had arrested a colleague who was found guilty of death of an under-trial in custody. But no action was taken against him. He was, on the other hand/ promoted and transferred'.

In short, it may be said that the organizations throw up more disincentives than rewards for right actions' making Blom remark that the administrators may become immoral and tend to shirk responsibility, the practice of which is so essential for high public service ethics.

\section{CONCLUSION}

From the discussion so far it is evident that Organizations in Nigeria are not effective in providing "conducive environment" for ethical administration. The organizational culture which should reflect and reinforce value commitments has been weakened due to various developments. The following general inferences can be drawn.

1. The demands of organizations influence human behavior. The hierarchical structure reinforces target-orientation and rule-orientation of the administrators. The set goals of the organization and the laid out methods to reach them make the administrators less consultative' and non-innovative. Since reaching goals is taken as the measure for performance appraisal administrators concentration is more on 'reaching' them within stipulated time irrespective of the enquiry whether people are benefitted by administrative actions or not?

2. Over the years the quality of leadership - both within the hierarchy and without it (political) - has deteriorated. There is decrease in the instances of exemplary leadership behavior guiding and 'shaping' the new generation into the 'norms and values of the services'. On the 
contrary the younger generation feels that necessary attention is not being paid by the seniors to their administrative problems and ethical dilemmas.

3. Professional Associations are not effective in ensuing high ethical standards in administration. They do not support their member's actions from undue external pressures. Similarly neither do they lay down specific codes of ethics for members nor do they enforce the already existing codes like their counterparts in USA. Lack of unity has weakened the associations incapacitating them from any effective action.

4. Reward (punishment) practices to promote ethical behavior, by recognizing the individual efforts and integrity of action, are distorted by factors external to the organization, mainly the political system (discussed in the next chapter). They are decided by the political functionaries on the basis of 'co-operation' and 'non-co-operation' rather than by merit of action. This, to a great extent hinder ethical actions'. It drives administrators to be more cynical and amoral though not immoral.

5. Ethics institutions are vast covering all aspects of immorality. The administrators' familiarity with codes of ethics is high but their 'acceptability' appears to be not into expected level due to various "external factors which force administrators to accommodate various factors in their functioning" At the same time the enforcing agencies have not succeeded in their Directives as they, in themselves, are not free from corruption, immorality and political interference. Also the Professional Associations in Nigeria unlike in USA, have not accepted the responsibility of sensitizing the administrators in ethical aspects of governance by laying down and enforcing agency specific codes. Infact; they can become more effective than separate agencies established externally as they function in an informal way. In short Organizations do not present conducive environment to encourage ethical action in administration whatever are the reason.

\section{REFERENCES}

Adesopo, A. (2013). Consolidating Nigerian Democracy: Time to Enhance Ethics and Accountability Systems of the State Bureaucratic Institutions. International Journal of Humanities and Social Science, 3(15). Retrieved from http://www.ijhssnet.com/journals/Vol_3_No_15_August_2013/22.pdf

Agbin, \& Chukwujioke, K. (2018). Effect of ethical leadership on corporate governance, performance and social responsibility: a study of selected deposit money banks in Benue State, Nigeria. International Journal of Community Development \& Management Studies, $2,19-35$.

Akinmayowa, J. T. (2008). Business ethics and marketing practices in Nigeria. In Business Practices in Emerging and Re-Emerging Markets (pp. 89-115). https://doi.org/10.1057/9780230611016

Akpakip, C. E. (2017). Effect of Workforce Diversity on Employee Performance in Nigerian Banking Industry. Business Ethics, 2, 23-46.

Ali Ibbi, A. (2016). The Battle for Professionalism in Journalism in Nigeria amidst Unethical Practices. Journal of Mass Communication \& Journalism, 06(03). https://doi.org/10.4172/2165-7912.1000301 
Blom, R. (2019). Naming crime suspects in the news: "Seek truth and report it" vs. "Minimizing Harm." In Media Controversy: Breakthroughs in Research and Practice (pp. 354-372). https://doi.org/10.4018/978-1-5225-9869-5.ch020

Daramola, I. (2013). Ethical and Legal Issues Consideration in Public Affairs Reporting: A Study of Parliamentary Reporting in Nigeria. Oman Chapter of Arabian Journal of Business and Management Review, 2(10), 62-70. https://doi.org/10.12816/0002335

Duke, E. O. (2018). „Eyen mi nyamkkenyam, nnọ ke ndọ...’: Deconstructing Some Stereotypic Views on Marriage in Efik Culture.

Duke, E. O. (2019). From Christian spirituality to eco-friendliness.

Dumbili, E. W., \& Sofadekan, A. (2016). "I collected money, not a bribe": Strategic ambiguity and the dynamics of corruption in contemporary Nigeria. Social Sciences, 5(3). https://doi.org/10.3390/socsci5030036

Ewing, A. C. (2013). The morality of punishment: With some suggestions for a general theory of ethics. In The Morality of Punishment: With Some Suggestions for a General Theory of Ethics. https://doi.org/10.4324/9780203094853

Eze, M. N. (2015). Value for Money Audit: an Accountability Tool in the Nigeria Public Sector. International Journal of Economics, Commerce and Management United Kingdom, 3(6), $1537-1544$.

Gabriel, Y. (1999). Ethics and Organizations. Management Learning, Vol. 30, pp. 493-497. https://doi.org/10.1177/1350507699304007

Hunter, R. D. (2012). Ethics for Organizations. In Contracts for Engineers (pp. 227-253). https://doi.org/10.1201/b11249-15

Kweon, M.-Y. (2017). The Reward and Punishment points ("Green Mileage") system in light of Nietzsche's Theory of Punishment. Journal of Ethics Education Studies, 46, 37-64. https://doi.org/10.18850/jees.2017.46.02

Nwabuzor, A. (2005). Corruption and development: New initiatives in economic openness and strengthened rule of law. Journal of Business Ethics, 59(1), 121-138. https://doi.org/10.1007/s10551-005-3402-3

Okotoni, C. A. (2015). Ethical dimensions in educational administration in Nigeria. International Journal of Educational Organization and Leadership, 21(1), 15-24. https://doi.org/10.18848/2329-1656/cgp/v21i01/48491

Omilusi, M. (2018). Beyond sloganeering and damage control mechanism: the vicious circle of ethical transformation and value re-orientation campaigns in Nigeria. Sociology International Journal, 2(2). https://doi.org/10.15406/sij.2018.02.00035

Pilatti, L. (2006). Managerial Ethics: the ethics in the enterprise organizations. Journal of Technology Management \& Innovation, 1(5), 7-75.

Pullen, A., \& Rhodes, C. (2015). Ethics, embodiment and organizations. Organization, 22(2), 159-165. https://doi.org/10.1177/1350508414558727. 
$224 \mid$ Pinisi Discretion Review

Volume 3, Issue 2, March, 2020 Page. 217- 224

Rhees, R. (2013). Ethical reward and punishment. In Value and Understanding: Essays for Peter Winch (pp. 179-193). https://doi.org/10.4324/9780203713686

Salam, E. A., \& Musa, Y. Y. (2017). Intra-party democracy in Nigerian political parties: A historical survey. In 2017 6th International Conference on Government, Law and Culture (ICGLC 2017). Retrieved from http://irep.iium.edu.my/54439/

Solomon, R. C. (2004). Aristotle, ethics and business organizations. Organization Studies, Vol. 25, pp. 1021-1043. https://doi.org/10.1177/0170840604042409 